\title{
Independent, Compulsory, and Centralized Verification of States' Obligations in Fisheries: Can the I mo Audit Scheme for Shipping Law Be Used as an Example to Follow?
}

\author{
Solène Guggisberg \\ Senior Research Associate, Netherlands Institute for the Law of the Sea, \\ Utrecht University, Utrecht, Netherlands \\ Senior Nereus Fellow, Nippon Foundation \\ s.a.guggisberg@uu.nl
}

\begin{abstract}
Marine fisheries are in crisis. One of the causes of this problem is the inability or unwillingness of some states to abide by the international rules binding them. No comprehensive and compulsory mechanism exists to review states' compliance with these obligations. This is in stark contrast with the shipping field, where International Maritime Organization (IMO) member states are regularly audited: the respect of their obligations as flag, coastal, and port states is assessed by external and professional auditors through a detailed procedure. Transposing at least some features of the IMO Audit Scheme, such as comprehensiveness, regularity, predictability, and centralization to the review of compliance with fisheries-related obligations would be highly desirable. While there may be challenges ahead - in particular when it comes to a mandatory scheme - there does not appear to be insurmountable issues to developing a comprehensive audit in the fisheries field.
\end{abstract}

\section{Keywords}

international fisheries law - compliance - International Maritime Organization (IMO) Compulsory Member State Audit Scheme - Food and Agriculture Organization (FAO) 


\section{Introduction}

Illegal, unreported and unregulated (IUU) fishing has multiple and interrelated causes and drivers, such as economic advantages for those actors disregarding the rules, excess fishing capacity, subsidies, ineffective fisheries management, or inadequate monitoring, control and surveillance. ${ }^{1}$ At its basis however, and also behind the more encompassing problem of unsustainable fishing, remains a single issue: many states involved in fisheries conservation and management appear unwilling or unable to comply with their international obligations in the field. This can be best illustrated by the long-standing issue of flag states failing to comply with international rules ${ }^{2}$ and the dwindling stocks in coastal waters and within other areas under fisheries management regimes. ${ }^{3}$

States have a variety of duties with regard to fishing activities, which are related to the different roles they play, as flag state, coastal state, port state, or state cooperating in the conservation and management of a fishery. Central to the regulatory regime is that the flag state must control its vessels and ensure that they respect the applicable conservation and management measures (CMMs). The obligation is provided for in the UN Convention on the Law of the Sea (UNCLOS) in Article $94^{4}$ and further elaborated, in relation to the fisheries

1 On the causes of IUU fishing, see for example Rachel Baird, "Illegal, Unreported and Unregulated Fishing: an Analysis of the Legal, Economic and Historical Factors Relevant to its Development and Persistence", 5 Melbourne Journal of International Law (2004) pp. 299-334; Betrand Le Gallic and Anthony Cox, "An economic analysis of illegal, unreported and unregulated (IUU) fishing: Key drivers and possible solutions", 30 Marine Policy (2006) pp. 689-695; Carl-Christian Schmidt, "Economic Drivers of Illegal, Unreported and Unregulated (IUU) Fishing", 20 The International Journal of Marine and Coastal Law (2005) pp. 479-507; Kuan-Hsiung Wang, "In Combating and Deterring IUU Fishing: Do RFMOs Work?", in C.H. Schofield, S. Lee, and M.-S. Kwan, (eds.), Limits of Maritime Jurisdiction (2013) pp. $43^{2-433}$.

2 On the issue of flags of convenience and fishing, see for example Darren S. Calley, Market Denial and International Fisheries Regulation: The Targeted and Effective Use of Trade Measures Against the Flag of Convenience Fishing Industry (2011) in particular chapters 2 and 3; Matthew Gianni and Walt Simpson, "Flags of Convenience, Transhipment, Re-Supply and At-Sea Infrastructure", in OECD, Fish Piracy (2004); Deirdre Warner-Kramer, "Control Begins at Home: Tackling Flags of Convenience and IUU Fishing”, 34 Golden Gate University Law Review (2004) pp. 497-530.

3 Over 33 per cent of stocks are overfished, nearly 6o per cent are fully-fished, and only about 7 per cent currently remain underfished (Food and Agriculture Organization (FAO), The State of the World Fisheries and Aquaculture (2018) p. 6).

4 UN Convention on the Law of the Sea (1982) 1833 UNTS 3 (UNCLOS). 
sector, in other treaties. ${ }^{5}$ Coastal states must ensure that the resources under their jurisdictions are not over-exploited. ${ }^{6}$ Both coastal states - when dealing with fish stocks not exclusively located in their waters - and the flag states of vessels active on the high seas are under an obligation to cooperate in the conservation of marine living resources. ${ }^{7}$ UNCLOS does not state which form such cooperation should take, but states have, in practice, generally entered into agreements setting up regional fishery bodies. Some of these, known as regional fisheries management organizations (RFMOs), adopt binding CMMS. The UN Fish Stocks Agreement (UNFSA) recognizes RFMO s as the vehicle for cooperative management of straddling and highly migratory stocks. ${ }^{8}$ As to port states, they are not under any general obligation under UNCLOS, but parties to the Agreement on Port State Measures to Prevent, Deter and Eliminate Illegal, Unreported and Unregulated Fishing (PSMA) must deny entry into port to vessels involved in IUU fishing, or inspect vessels entering their ports and, if they determine that relevant CMM s were violated, deny the use of port services to such vessels. ${ }^{9}$

The traditional regime regulating fisheries is highly fragmented, with detailed rules found in a variety of treaties (many of which are regional rather than global, and binding some states but not others). ${ }^{10}$ Even if one focuses on the global level, it is generally accepted that compliance with the existing rules binding states is not satisfactory. At present, the mechanisms in place to verify that states in fisheries respect the rules binding them in their different capacities suffer many deficiencies. They are fragmented, not comprehensive, not always independent, often non-binding, and trigger little, unclear, or no consequences in cases of non-compliance with the substantive obligations at stake. Hence, a first step to improving this situation would be the creation of comprehensive, compulsory, and independent procedures to control states'

Agreement to Promote Compliance with International Conservation and Management Measures by Fishing Vessels on the High Seas (1993) 2221 UNTS 120 (Compliance Agreement); Agreement for the Implementation of the Provisions of the United Nations Convention on the Law of the Sea of 10 December 1982 relating to the Conservation and Management of Straddling Fish Stocks and Highly Migratory Fish Stocks (1995) 2167 UNTS 88 (UNFSA).

6 Art. 61(2) UNCLOS.

7 Arts. $63-64,118$ UNCLOS.

8 Art. 8 UnFSA.

9 FAO Agreement on Port State Measures to Prevent, Deter and Eliminate Illegal, Unreported and Unregulated Fishing (2009) 55 ILM 1157 (PSMA) arts. 9, 11 <http://www.fao.org/file admin/user_upload/legal/docs/o37t-e.pdf>.

10 Even global treaties are not ratified as widely as UNCLOS. As of December 2019, there were 42 parties to the Compliance Agreement and 90 parties to UNFSA. 
compliance with their obligations. Such procedures would allow states to take stock of their behaviour and the international community, on the basis of established facts, to encourage compliance and/or respond to instances of noncompliant behaviour.

The weak compliance system in fisheries is in stark contrast with the regime in place to regulate shipping. Through the last quarter century, a complex review mechanism has been developed under the ambit of the International Maritime Organization (IMO) to verify compliance of states involved in shipping with their obligations. Since fishing and shipping are both activities at sea, in relation to which states have obligations in their capacities as flag, coastal and port states, one could expect that the relevant regulatory regimes could inspire each other, if not in substantive terms, at least with regard to procedures.

With that general aim in mind, the present article will present the procedures currently in place in relation to fisheries obligations and then examine the equivalent mechanism in the shipping field. This will serve as a basis to analyse whether a similar structure, or features thereof, would be desirable in the regulatory regime of fisheries, and to discuss whether it could be transposed therein. This article focuses on the mechanisms to verify states' compliance with their obligations, not on the adequacy of the obligations themselves. Moreover, while comparing the existing procedures with compliance systems set up under multilateral environmental agreements ${ }^{11}$ would certainly yield interesting results, ${ }^{12}$ this falls beyond the scope of this research.

\section{$2 \quad$ Existing Procedures: a Comparison}

\subsection{Fisheries Regime ${ }^{13}$}

As mentioned, the fisheries regime is characterized by its fragmentation, a challenge which is not only noticeable in terms of substantive law, but also when

11 On existing compliance systems under multilateral environmental agreements (MEAs), see in particular Geir Ulfstein, Thilo Marauhn and Andreas Zimmermann (eds.), Making Treaties Work (2008) chapters 5 to 9. See also Peter G.G. Davies, "Non-Compliance - A Pivotal or Secondary Function of COP Governance", in M. Fitzmaurice, International Environmental Law (2015) pp. 87-115; Rosalind Reeve, Policing International Trade in Endangered Species: the CITES Treaty and Compliance (2004).

12 A comparison of MEAs and RFMOs procedures was undertaken by María Cecilia Engler Palma in the article "Non-Compliance Procedure: Can Regional Fisheries Management Organizations Learn from the Experience of Multilateral Environmental Agreements?", 24 Ocean Yearbook (2010) pp. 185-237.

13 This section relies on past publications of the author, in particular Solène Guggisberg, "Recent Developments to Ensure Compliance with International Fisheries Law", 42 
it comes to institutional arrangements and review procedures. There is no one body or procedure to verify that states fulfil their obligations in relation to fishing. While the Committee on Fisheries (COFI) of the Food and Agriculture Organization (FAO), ${ }^{14}$ the UN General Assembly with its annual Sustainable Fisheries Resolution, ${ }^{15}$ and the UNFSA (Resumed) Review Conference ${ }^{16}$ all provide forums for regular discussion of fisheries issues at the global level, they do not amount to comprehensive reviews of states' compliance with their international obligations.

Nevertheless, some procedures exist to gather information about states' respect of their obligations, separately as flag state, port state, and as state cooperating within an RFMO. As to coastal states, while they have important obligations to attain sustainable fisheries, they enjoy a quasi-total discretion in how - and hence whether - they implement the relevant provisions of UNCLOS. This absence of any procedure with regard to states entrusted with such crucial roles as coastal states means that, even if the other mechanisms in place provided a universal and qualitative review of states' compliance, the overall regime would still lack in comprehensiveness. The existing procedures, however, also suffer some weaknesses.

First, a procedure to review flag state compliance with their obligations has been developed in the 2014 FAO Voluntary Guidelines for Flag State Performance (VGFSP). ${ }^{17}$ This soft-law instrument brings together substantive and procedural provisions. It lists, in the form of performance assessment criteria, the most accepted obligations of flag states. ${ }^{18}$ It also suggests procedures

Observateur des Nations Unies (2017) pp. 139, 145-175 and Solène Guggisberg, "Verifying and improving states' compliance with their international fisheries law obligations", in A.M. Cisneros-Montemayor, W.W.L. Cheung and Y. Ota, Predicting Future Oceans (2019) pp. $453-464$.

14 The most recent of these biennial meetings took place in July 2018; see $\mathrm{COFI}_{33}$ Documents for an overview of the issues discussed <http://www.fao.org/about/meetings/cofi/ documents-cofiz3/en/>.

15 The most recent of these yearly resolutions is UNGA, A/4/L.21, "Sustainable fisheries, including through the 1995 Agreement for the Implementation of the Provisions of the United Convention on the Law of the Sea of 10 December 1982 relating to the Conservation and Management of Straddling Fish Stocks and Highly Migratory Fish Stocks, and related instruments", 10 December 2019.

16 The most recent occurrence of this procedure, which has so far taken place every four to six years, led to the Report of the 2016 UNFSA Resumed Review Conference (2016), A/CONF.210/2016/5.

17 FAO, "Voluntary Guidelines for flag State performance" (2015)<http://www.fao.org/ 3/a-i4577t.pdf>.

18 Ibid., paras 2, 6-43. 
for carrying out assessments and measures to promote compliance. ${ }^{19}$ It finally describes the role to be played by the FAO. ${ }^{20}$ Inter alia, states should inform the FAO of their assessments and the results thereof as part of their biennial reporting on the 1995 Code of Conduct for Responsible Fisheries (CCRF). According to the 2018 CCRF questionnaire, 23 states have thus far undertaken a flag state assessment, and 48 others have expressed their intention to engage a review process in the future. ${ }^{21}$

Since the VGFSP are voluntary in nature, states are under no obligation to undertake a review of any sort. If they decide to do so, they remain free to choose how to assess their performance. The VGFSP envisage both options of self-review and external assessment. This instrument does not indicate how reviewers may be chosen. As to the criteria against which a state's conduct should be assessed, one can expect them to be the ones listed in the VGFSP. However, this is only made explicit for external assessments, which implies that states can freely use different criteria if they choose to undertake a self-assessment. The VGFSP do not fully clarify whether there are immediate consequences and what the nature of such consequences would be - to an assessment finding that a flag state is performing poorly. This instrument lists a number of facilitative and enforcement-like measures which may be adopted, but provides no procedural certainty as to the order in which such measures can be applied, or as to the level of underperformance which would trigger them.

Second, port states do not have, per se, obligations related to fisheries under the general law of the sea. However, they have progressively developed as important actors to tackle issues triggered by some flag states' inability or unwillingness to respect their obligations. Originally developed in the field of vessel safety and the prevention of pollution, port state controls have gradually been extended to the field of fisheries. ${ }^{22}$ They now are the focus of a dedicated treaty, the PSMA of 2009, which entered into force in 2016. In addition to its substantive content, the PSMA institutionally sets up a procedure to verify states' compliance with their obligations under the treaty. This treaty indeed requires,

\footnotetext{
19 Ibid., paras $44-47$.

$20 \quad$ Ibid., paras $56-58$.

21 Regional Statistical Analysis of Responses by FAO Members to the 2018 Questionnaire on the Implementation of the Code of Conduct for Responsible Fisheries and Related Instruments, COFI/2018/sBD.1, p. 55, table 67 <http://www.fao.org/3/CAo465EN/cao465 en.pdf $>$; Guggisberg 2019 (supra note 13) p. 456.

22 Judith Swan, "Port State Measures - from Residual Port State Jurisdiction to Global Standards", 31 The International Journal of Marine and Coastal Law (2016) pp. 395, 400-407.
} 
"within the framework of FAO and its relevant bodies, ... the regular and systematic monitoring and review of the implementation of this Agreement". ${ }^{23}$

At the first meeting of the parties, it was agreed that a specific web-based questionnaire would be developed and that it would be filled, every other year, by each state reporting on its own implementation of the PSMA. ${ }^{24}$ The questionnaire was adopted in June 2019; the evaluation criteria are based on the treaty and are the same for all parties. It will be circulated for the first time mid-2020. ${ }^{25}$ The FAO Secretariat has been mandated to conduct a quantitative analysis of the reports received from states. Hence, elements of independent review may accompany self-reporting. All states parties have to comply with the procedures to monitor their implementation of the PSMA since the treaty explicitly provides for such review. However, it is unclear, at this stage, whether the FAO will identify those states which fail to answer or fail to implement the PSMA - and what the consequences might be.

Third, RFMOs have been entrusted with managing and conserving straddling and highly migratory fish species. Their role is central to fisheries management, but their track record has been widely criticized. ${ }^{26}$ In response to the recognized need for improvement, a voluntary process known as RFMO performance review was developed and gradually embraced by RFMOs. This procedure enables a panel of experts to assess how well a specific RFMO is fulfilling its functions, comparing the situation to a set of benchmark criteria. Since the mid-20oos, performance reviews have been undertaken by most RFMO s and some have already finalized a second assessment. ${ }^{27}$ The reports of these panels are publicly available.

\section{Art. 24(1) PSMA.}

24 "Report of the first meeting of the Parties to the Agreement on Port State Measures to Prevent, Deter and Eliminate Illegal, Unreported and Unregulated Fishing (Oslo, 29-31 May 2017)", Fisheries and Aquaculture Report No. 1211 (2017) paras 36-37.

25 "Report of the second meeting of the Parties to the Agreement on Port State Measures to Prevent, Deter and Eliminate Illegal, Unreported and Unregulated Fishing (Santiago, 3-6 June 2019)", Fisheries and Aquaculture Report No. 1272 (2019) para 27.

26 See for example FAo, "The State of the World Fisheries and Aquaculture" (2016) p. 8; see also Sarika Cullis-Suzuki and Daniel Pauly, "Failing the high seas: A global evaluation of regional fisheries management organizations", 34 Marine Policy (2010) pp. 1036-1042; Michael W. Lodge et al., Recommended Best Practices for Regional Fisheries Organizations (2007) p. ix.

27 On the performance reviews conducted so far, see "Report of the Secretary-General to the 2016 UNFSA Resumed Review Conference" (2016), A/CONF.21o/2016/1, paras 161-162; FAO, "The State of the World Fisheries and Aquaculture" (2018) p. 79. The recently established South Pacific RFMo (SPRFMo) has finalized its first performance review in December 2018 (see sPRFMO, "Performance Review of RFMOs" < https://www.sprfmo. int/about/the-convention/sprfmo-review-2018/>). 
RFMOs are independent international organizations, and as such do not have to file reports with any supervising body that would assess their compliance in a centralized manner. They are free to choose the composition of the review panel as they wish. Practice differs as between institutions, with some having selected a mix of representatives from the RFMO or their member states and external experts, and others having preferred a purely external group of people. ${ }^{28}$ It appears that, so far, all panels have included at least one independent expert. The criteria used to assess RFMOs' performance are similar across institutions, although they ultimately depend on the terms of reference developed by each RFMO. In practice, all the performance reviews seem to be based on the minimum standards agreed upon in 2007 within the Kobe process, an ongoing collaboration of the tuna RFMOs on issues of common interest. ${ }^{29}$

Except for one RFMO, the decision to undergo a performance review remains voluntary; only the South Pacific RFMO (sPRFMO) provides in its founding instrument that a review procedure must be undertaken at least every five years. ${ }^{30}$ Once the performance review is finalized, most RFMOs set up a framework to implement, or at least examine, the recommendations made by the review panel. No external institution is tasked with overseeing the extent to which recommendations are ultimately taken into account and whether progress can be considered timely. Second performance reviews start by assessing whether and how the recommendations of the first review have been implemented. ${ }^{31}$ This ensures that, at the very least, some pressure is kept on RFMO s to act upon recommendations.

In summary, the mechanisms in place to review compliance of flag and port states, and states parties to an RFMO are diverse and independent from each other. Some are voluntary and ad hoc, while others must be undertaken at

28 Marika Ceo et al., "Performance Reviews by Regional Fishery Bodies: Introduction, summaries, synthesis and best practices, Volume I: CCAMLR, CCSBT, ICCAT, IOTC, NAFO, NASCO, NEAFC", FAO Fisheries and Aquaculture Circular No. 1072 (2012); Péter D. Szigeti and Gail Lugten, "The Implementation of Performance Review Reports by Regional Fishery Bodies, 2004-2014", FAO Fisheries and Aquaculture Circular No. 1108 (2015).

29 FAO, "The State of the World Fisheries and Aquaculture" (2018) p. 79.

30 Convention on the Conservation and Management of High Seas Fishery Resources in the South Pacific Ocean (2009) art. 30.

31 See for example the Terms of Reference and criteria to conduct the Second Performance Review of the готс, in "Report of the Eighteenth Session of the IOTC" (2014) appendix XVI; CCAMLR, "Report of the Thirty-fifth Meeting of the Commission (Hobart, Australia, 17-28 October 2016)" (2016) annex 8; ICCAT, "Approach to a Second Review of ICCAT", annex $1<$ https://www.iccat.int/intermeetings/Performance_Rev/ENG/PER_FINAL_TOR ENG.pdf>. 
regular intervals. All of them appear, at the very least, to recommend the use of similar criteria to assess performance and to promote a level of independence in the review process, but in certain cases, the freedom to do otherwise remains. None of the mechanisms described above have clear procedures in place to verify that improvements follow a sub-standard assessment, to promote change by way of facilitative support linked to the review, or if necessary, to implement sanctions against states failing to modify their behaviour or refusing to be evaluated.

\section{$2.2 \quad$ Shipping Regime}

The Imo implements and oversees what is now a compulsory, regular, and comprehensive review of its member states' compliance with their obligations in relation to shipping, be it as flag, coastal, or port state. This complex mechanism, in place in its current form since 2016, has developed throughout the best part of two decades. ${ }^{32}$

Already in the early 1990s, the IMO was aware that improvements were needed regarding flag states' implementation of their obligations in the shipping field. This led to the establishment of the Flag State Implementation Sub-Committee. ${ }^{33}$ In 1999, the Sub-Committee put in place a procedure to encourage states to examine their performance as flag states. It was organized as an assessment form to be filled by the flag state itself and was voluntary. ${ }^{34}$ Such self-evaluation procedure lasted until 2005, when it was replaced by the Member State Audit Scheme. In total, 58 states submitted their forms to the IMO; these states represented over 8 o per cent of world tonnage, but some flag states of importance did not participate in the process. ${ }^{35}$

At the end of 2003, the IMO Assembly adopted a Resolution providing for the development of a Voluntary Member State Audit Scheme, ${ }^{36}$ the framework and procedures of which were adopted in $2005 .{ }^{37}$ This scheme verified that necessary laws had been enacted and that states, in practice, implemented

32 On the development of the Imo Audit Scheme, see Lawrence Barchue, "Making a Case for the Voluntary Iмо Member State Audit Scheme" <http://www.imo.org/en/OurWork/ MSAS/Documents/Voluntary.pdf $>$; Henning Jessen and Ling Zhu, "From a voluntary self -assessment to a mandatory audit scheme: monitoring the implementation of IMO instruments", 3 Lloyd's Maritime and Commercial Law Quarterly (2016) pp. 389-411. James Harrison, Saving the Oceans Through Law: The International Legal Framework for the Protection of the Marine Environment (2017) p. 143.

34 Iм0, A.881(21), "Self-Assessment of Flag State Performance", 25 November 1999.

35 Jessen and Zhu (supra note 32) pp. 396-397.

36 Imo, A.946(23), "Voluntary IMO Member State Audit Scheme", 27 November 2003.

37 IMO, A.974(24), "Framework and Procedures for the Voluntary IMO Member State Audit Scheme", 1 December 2005. 
and enforced the relevant IMO standards. ${ }^{38}$ It addressed obligations not only as flag state, but also as port and coastal state. Like the procedure it replaced, this scheme was applicable on a voluntary basis. For those states that accepted to be audited, the review was undertaken by external auditors. The Voluntary Audit lasted until 2016, when it was transformed into a Mandatory Audit. In total, 75 voluntary audits were performed. ${ }^{39}$

In 2013, the IMO Assembly adopted a Resolution on the transition from the Voluntary Member State Audit Scheme to the Compulsory Member State Audit Scheme. ${ }^{40}$ Over the course of the next two years, IMO instruments, such as the Convention on the International Regulations for Preventing Collisions at Sea (COLREG) of 1972 or the International Convention for the Safety of Life at Sea (SOLAS) of 1974, were amended in order to include references to the Mandatory Audit. ${ }^{41}$ The last amendments entered into force on 28 February 2018, rendering this revised scheme fully workable..$^{42}$ In practice, and as will be developed here below, the Mandatory Audit functions in the same way as the Voluntary Audit had. The major difference is that IMO member states now cannot opt out of this process, which will review each state's performance at least every seven years. ${ }^{43}$ In the last three years, 78 mandatory audits were performed. ${ }^{44}$

The criteria used by auditors to assess states' performance can be found in the Implementation of Imo Instruments (III) Code (III Code). ${ }^{45}$ This Code, adopted in 2013 by the IMO Assembly as a Resolution, reflects the various standards spread out in a large number of Imo treaties and instruments, regrouping them under four thematic groups: common areas, flag states, coastal states, and port states. ${ }^{46}$ In charge of the performance assessment are external auditors, chosen from a pool of experts nominated by member states and

$38 \quad$ Harrison (supra note 33) p. 144.

39 IMO, "Reports Overview, Voluntary and Transitional Reports" <https://gisis.imo.org/ Public/MSA/ReportsOverview.aspx $>$. Jessen and Zhu (supra note 32 ) list 74 audits, a discrepancy which may result from a late reporting of one of the 2015 audits. IMO, A.1068(28), "Transition from the Voluntary Imo Member State Audit Scheme to the Imo Member State Audit Scheme", 4 December 2013.

41 Convention on the International Regulations for Preventing Collisions at Sea (1972) 1050 UNTS 16, rule 41; International Convention for the Safety of Life at Sea (1974) 1184 UNTS 278 chapter XIII (SOLAS). IMO, A.31(9) "IMO Member State Audit Scheme - Report on the implementation of the Scheme - Note by the Secretary-General", 13 September 2019, para 3. Imo, A.1067(28) "Framework and Procedures for the Imo Member State Audit Scheme", 4 December 2013, Part II, para 4.1.1.

44 IMO, "Reports Overview, Mandatory Reports" < https://gisis.imo.org/Public/MSA/Reports Overview.aspx $>$.

45 IMO, A.1067(28), Part I, para 3.1.

46 IMO, A.1070(28), "IMO Instruments Implementation Code", 4 December 2013. 
vetted by the Imo Secretary-General so that they meet a set of minimum technical requirements. ${ }^{47}$

The whole procedure starts with a preparatory phase, where the member state to be audited and the IMo Secretary-General enter into a Memorandum of Cooperation, outlining the scope of the audit and the responsibilities of each party during the audit. ${ }^{48}$ The team members and leader are chosen by the Imo Secretary-General, subject to the member state's agreement. ${ }^{49}$ The member state must fill in and return a pre-audit questionnaire, which, together with any other information provided by it, will serve as background information for the audit team. ${ }^{50}$ The audit itself is then conducted with a review of relevant national legislation and policy frameworks, and an on-site visit. ${ }^{51}$ All throughout, it is recommended that the audit team provide feedback, to assist the member state in devising solutions to its potential problems and to ensure that the member state is aware of the audit's findings. ${ }^{52}$ These findings are then formally included in an audit interim report, made available only to the member state and the IMo Secretary-General. ${ }^{53}$ On this basis, the member state must develop a corrective action plan within 9o days of receiving the interim report. ${ }^{54}$ Finally, the audit team must prepare the audit final report, similar to the interim report but also presenting the corrective action plan and its implementation, as well as any issues potentially left unresolved. ${ }^{55}$

A follow-up will take place once the member state has implemented all corrective actions, but not later than three to four years after the audit. Generally a desk-based review, the follow-up may include an on-site visit if needed, and if accepted by the member state. ${ }^{56}$ The audit is focused on facilitative measures, with the identification of areas where improvements are needed and the provision of technical assistance. ${ }^{57}$ At the IMO, support for member states is available through the Integrated Technical Cooperation Programme, ${ }^{58}$ which

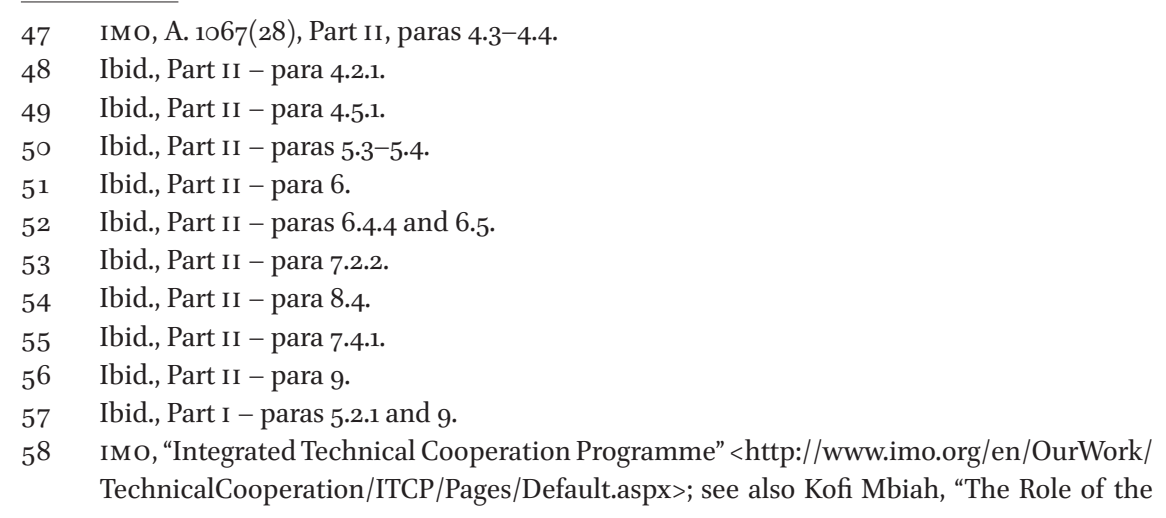


is referred to in the framework and procedure for the audit. ${ }^{59}$ The Audit Scheme, already when it was voluntary, was advertised as a way to "help to identify where capacity-building activities would have the greatest effect". ${ }^{60}$

No sanction is built in the audit scheme if a state refuses an audit or fails to implement its corrective action plan. Peer pressure or "naming and shaming" are unlikely to fully mitigate this situation, in particular with regards to potential substantive shortcomings. Indeed, except if the member state has agreed otherwise, the final report will remain confidential - the general public or even the other IMO member states will only have access to the audit report with the explicit approval of the audited state. In practice, however, one should note that all audited states have, so far, agreed to their corrective action plan and executive summary reports transmitted to the other IMO member states. ${ }^{61}$ Information about a blank refusal to undertake an audit would be known by states and the general public: a publicly available website lists past audits, ${ }^{62}$ and annual reports by the Imo Secretary-General provide similar information as well as a list of countries with audits pending. ${ }^{63}$

In summary, the IMO Audit Scheme covers all roles a state may play in the shipping field. It is a compulsory and regular procedure, undertaken by independent and professional auditors. The procedure itself is not only established and predictable, but it also takes into account the audited state's preferences with regards to key components. A follow-up of the corrective action plan's implementation ensures a certain level of long-term accountability. The results of the audit also feed into technical cooperation, providing willing states with the means to improve. In practice, there is some transparency with regard to the audit process, but any information of substance remains confidential, except if the audited state wishes otherwise.

International Maritime Organization in the Development of Maritime Law and Policy", in M.Q. Mejia (ed.), Selected Issues in Maritime Law and Policy (2013) p. 15.

59 Imo, A.1067(28), preamble.

6o "Voluntary audit scheme adopted at IMO's 24th Assembly" IMO News (January 2006) pp. 18-19, as presented in Sabine Campe, "The Secretariat of the International Maritime Organization: A Tank for Tankers", in F. Biermann and B. Siebenhüner (eds.), Managers of Global Change - The Influence of International Environmental Bureaucracies (2009) p. 15 o.

61 IMO, A 31/9, "IMO Member State Audit Scheme - Report on the implementation of the Scheme - Note by the Secretary-General", 13 September 2019, para 13.

62 The website is open to all, but users have to register to access information: IMO, "GISIS: Member State Audits" <https://gisis.imo.org/Public/MSA/ReportsOverview.aspx>.

63 Iмо, A.31/9. 


\subsection{Desirability of an IMо Audit-like Scheme}

An Iмо Audit-like scheme has many advantages compared to the review procedures available in the fisheries field. It is an independent, comprehensive, and mandatory review of states' compliance with their obligations. Using independent auditors instead of letting the actor under assessment report on itself (or relying on a review from an insider) contributes to a procedure free of bias and conflicts of interest. That auditors are selected from a list of vetted experts also ensures that a level of professionalism is built in the system - great professionalism has often been shown in ad hoc appointments, but it cannot be guaranteed. In terms of comprehensiveness, an Iмо Audit-like scheme would be valuable in two respects in the fisheries field: it would fill in the large gap relative to coastal states' obligations and it would ensure that all states are subject to the procedure, ultimately contributing to a real levelling of the playing field.

Such an audit scheme has the potential to provide an overview of where states stand with regard to relevant standards' implementation, with implications not only for individual states but also for the international community more generally. Results of individual audits can obviously guide states to take necessary measures to improve potential deficiencies. Moreover, technical support made available to individual states enables them to correct issues identified by the audits. A comprehensive, centralized, and regular audit scheme also provides for the potential development of a body of knowledge and practice through time and across the globe. The cumulative results of all audits indeed can help identify best practices to be replicated, allow a fact-based and fully informed allocation of support, and ultimately feed back into standard setting. Indeed, by providing data on rules which may be inefficient, unsuitable, or unclear, and hence in need of modification or additional development, an audit scheme may inform further policymaking by the relevant institutions.

Another desirable feature of the IMO Audit Scheme is the predictability of a very detailed procedure. Notwithstanding the content of the specific Memorandum of Cooperation between the IMO and the audited state, the general гмо Resolution presenting the framework and listing the procedural steps spans over 20 pages. Audited states also keep control over certain important decisions. In particular, they are able to veto auditors and have the opportunity to develop a corrective action plan before the audit final report is sent to the Imo Secretary-General. Procedural certainty and ownership are key features to a well-functioning review system. While the relevant mechanisms in the fisheries field are mostly in the hands of states, their consequences lack 
in predictability. This may create a disincentive for states to voluntarily undertake and share an assessment of their performance if the results risk being used against them.

However, there are also less positive aspects of the Imo Audit Scheme. In particular, its toothless nature means that, to a state willing to follow the procedure but unwilling to make substantive changes, the audit is a paper tiger. The lack of sanctions built into the mechanism and the absolute confidentiality of reports appear typical of the IMO functioning, which has not always resulted in high levels of state compliance with reporting obligations. ${ }^{64}$ Such features may have been necessary to render the audit acceptable to member states, but they may also weaken the scheme's overall effectiveness. The focus on facilitative measures relies on the assumption that states are unable, rather than unwilling, to comply with their obligations, a hypothesis which remains to be tested.

\subsection{Feasibility of Transposing an IMO Audit-like Scheme}

Whether an Imo Audit-like scheme can be transposed into the fisheries field ultimately depends on states' willingness to adopt such a procedure and to entrust an institution with its implementation. However, at present, a fullfledged compulsory audit scheme seems unlikely, for a variety of reasons. An important obstacle to transposing the Audit Scheme to fisheries is that the legal regimes in place for fisheries and shipping differ in many ways. This has implications with regards to the identity of the institution in charge of organizing and then implementing a potential audit scheme, to the voluntary or compulsory nature of such a scheme, and to the standards used as criteria for an assessment.

First, a global institution with sufficient resources and an adequate mandate must be involved in the development and implementation of a comprehensive and centralized audit scheme. In the shipping field, the Imo was the obvious candidate, as the global institution is empowered

to provide machinery for co-operation among Governments in the field of governmental regulation and practices relating to technical matters of all kinds affecting shipping engaged in international trade, and to encourage the general adoption of the highest practicable standards in matters concerning maritime safety and efficiency of navigation. ${ }^{65}$

64 Campe (supra note 6o) p. 156.

65 Convention on the International Maritime Organization (1948) 289 unTs 3, as amended (IMo Constitutive Convention) art. 1(a). 
Amongst other functions, the IMO oversees the drafting of treaties and other instruments, ${ }^{66}$ the implementation of which has gradually become one of its main focuses. ${ }^{67}$ Indeed, having seen the development of the instruments relevant to states' obligations in shipping, the IMo's role further expanded to supporting member states to comply with the relevant standards, ultimately through the Audit Scheme.

In comparison, there is no global institution specialized in fisheries. The most likely candidate remains the FAO, which supports its member states in eradicating hunger and malnutrition. ${ }^{68}$ This goal is in part to be achieved through the sustainable utilization of natural resources, including fish stocks. The FAO's functions are mainly to collect and disseminate relevant information, recommend action when appropriate, and provide technical assistance. ${ }^{69}$ COFI, a body open to FAO Members and non-member states, represents the major forum where governments discuss fisheries and aquaculture problems and where recommendations are made to all major stakeholders.

The FAO is also a forum for the development and adoption of treaties, ${ }^{70}$ and has done so for fisheries instruments, in particular the 1993 Agreement to Promote Compliance with International Conservation and Management Measures by Fishing Vessels on the High Seas (Compliance Agreement) and the 2009 PSMA. To the extent provided in these treaties, ${ }^{71}$ the FAO plays a role in overseeing their implementation. As examined above, it is also involved in the supervision of the VGFSP. These review powers, however, are fragmented and limited. Moreover, outside of the specific instruments referring to it, the FAO is not an umbrella organization to which states involved in fisheries must necessarily report in relation to their fisheries-related obligations. Nonetheless, the FAO is a long-standing clearinghouse when it comes to laws and policies

66 Art. 2(b) Imo Constitutive Convention.

67 Imo, A.1110(30), "Strategic Plan for the Organization for the Six-Year Period 2018 to 2023", 6 December 2017, Mission Statement; see also Mbiah (supra note 58) pp. 2-3; Efthimios E. Mitropoulos, "IMO - 6o years in the service of shipping", in N.A. Martínez Gutiérrez (ed.), Serving the Rule of International Maritime Law (2009) pp. 12, 20.

68 "Constitution", in Basic texts of the Food and Agriculture Organization of the United Nations (2017 ed.), preamble (FAO constitution) <http://www.fao.org/3/K8024E/K8024E .pdf\#page $=21 \&$ zoom $=100>$.

69 Art. I FAO Constitution.

70 Art. XIV faO Constitution.

71 The FAO has no such powers under the Compliance Agreement, but plays a role in the PSMA, as examined in part 2.1. 
in its areas of expertise; for example, it maintains legal databases related to domestic requirements for various aspects of fishing. ${ }^{72}$

Another potential issue to reproducing the IMO Audit under the ambit of the FAO is the importance of RFMOs. There is no hierarchy between the FAO and these regional institutions, except for two - the General Fisheries Commission for the Mediterranean and the Indian Ocean Tuna Commission - which were created under the FAo's auspices. States cooperating through RFMOs are usually protective of the independent nature of their organizations. However, the FAO plays some role through the Regional Secretariats Network in order to facilitate contacts between RFMO s on issues of common interest. ${ }^{73}$ Whereas RFMO member states may be reluctant to have (part of) their performance reviews centralized, such a transfer of competence could also be perceived as valuable if it enabled the assessment of non-cooperating non-contracting parties' respect for their obligations to cooperate in the conservation of fishery resources.

Second, the mandatory nature of the Imo Audit Scheme may be challenging to replicate. IMO instruments had to be amended in order to subject their parties to the Mandatory Audit Scheme, and this was done within a matter of years. Such widespread and rapid amendments seem unlikely in the field of fisheries. As the treaties relevant to detailed obligations in shipping are all IMO instruments, the biennial Imo Assembly or the relevant committees could serve as adequate forums to adopt the necessary amendments. Moreover, some of these treaties provide for a tacit amendment procedure, where an amendment, once adopted by the IMO committees, enters into force except if a certain number of states parties object to it. ${ }^{74}$ This enables treaty regimes to evolve quickly and in a manner that binds all parties, apart from objecting states. In comparison, in the field of fisheries, while some relevant treaties have been adopted at the FAO, others are independent from that international forum. This signifies that several separate international conferences would need to be convened in order to adopt amendments. ${ }^{75}$ Moreover, the tacit amendment procedure does not

72 FAO, "FAOLEX Database" <http://www.fao.org/faolex/en/>; FAO, "FISHLEX" <http:// extwprlegsi.fao.org/fishery/index.htm>; FAO, "Database on Port State Measures" <http:// www.fao.org/fishery/psm/collection/en>.

73 FAO, "Regional Fishery Body Secretariats Network (RSN)" <http://www.fao.org/fishery/ $\mathrm{rsn} / \mathrm{en}>$.

74 James Harrison, Making the Law of the Sea (2011) pp. 16o-164. See for example art. viII(b) SOLAS and IMO, MSC 93/22/Add/1, "Amendments to the International Convention for the Safety of Life at Sea", as amended, 22 May 2014.

75 For amendment procedures of FAO instruments, see art. XIII Compliance Agreement; art. 33 PSMA. For amendment procedures of other fisheries-related treaties, see art. 312 UNCLOS; art. 45 UNFSA. 
exist in these treaties, meaning that all states parties would have to ratify the amendments for them to be universally applicable among parties.

Whereas the necessary legal bases to establish a mandatory scheme are not forthcoming, this does not impair the development of a voluntary audit scheme. Amendments had not been a prerequisite to establishing the IMO Voluntary Audit Scheme. Instead, it relied on an Imo Assembly Resolution, adopted according to the Imo Constitutive Convention. The Assembly is indeed empowered

[t]o recommend to Members for adoption regulations and guidelines concerning maritime safety, the prevention and control of marine pollution from ships and other matters concerning the effect of shipping on the marine environment assigned to the Organization by or under international instruments, or amendments to such regulations and guidelines which have been referred to it. ${ }^{76}$

The FAO Conference, in turn,

may, by a two-thirds majority of the votes cast, make recommendations to Member Nations and Associate Members concerning questions relating to food and agriculture, for consideration by them with a view to implementation by national action. ${ }^{77}$

Hence, if they so choose, the 196 FAO member and associated states (and the European Union) could adopt a set of procedures to comprehensively review their obligations in the fisheries field through an audit.

Third, the development of a single set of standards, as encompassed in the III Code, may prove arduous. Indeed, the global frameworks applicable to fishing and shipping may be equally based on UNCLOS, but similarities stop there. Shipping rules are further detailed in widely ratified global treaties, which bind all states through the relevant rules of reference. Many UNCLOs provisions related to shipping indeed require states to conform to generally accepted international regulations; these rules, mostly found in IMO instruments, thus become binding on all UnCLOS parties. ${ }^{78}$ In comparison, the fisheries regime

$76 \quad$ Art. 15(j) Imo Constitutive Convention.

77 Art. IV(3) FAO Constitution.

78 See in particular art. 211 UNCLOS. On rules of reference, see for example Harrison (supra note 74) pp. 165-179; Bernard H. Oxman, "The duty to respect generally accepted international standards", 24 New York University Journal of International Law and Politics (19911992) pp. 109-159. 
involves fewer global treaties, and hence general obligations remain more vague. It is also more fragmented due to lower ratification levels of existing treaties and the absence of similar rules of reference in UNCLOS. Hence, the identification of the criteria to be included in a set of benchmarks reflecting generally applicable standards would not be simple transposition from several treaties to another single instrument.

Such identification of criteria would not, however, be impossible. It would rely on the interpretation of general obligations, taking into account detailed rules found in other treaties and instruments. The VGFSP, which were developed under the ambit of the FAO, exactly illustrate this scenario. They list the criteria of responsible flag states, and to do so encompass rules found in the Compliance Agreement and the CCRF. Moreover, while a unified set of criteria would greatly simplify the auditing process, it is no sine qua non condition to its existence. Even in shipping, IMO member states are only audited vis-à-vis the obligations binding upon them. ${ }^{79}$

\section{Conclusion}

In conclusion, transposing at least some features of the Imo Audit Scheme, such as comprehensiveness, regularity, predictability, and centralization to the review of compliance with fisheries-related obligations would be highly desirable. While there may be challenges ahead - in particular when it comes to a mandatory scheme - there does not appear to be insurmountable issues to developing a comprehensive audit in the fisheries field.

To move forward from the existing fragmented and non-comprehensive set of review procedures in the fisheries field, one would need not only a sponsor state or group of states to put the issue on the agenda, but also buy-in from the international community. Guarantees of procedural certainty and fairness could be strong incentives for states, in particular those threatened with or facing unilateral trade sanctions. While such measures are usually the result of long dialogue procedures which seem to guarantee due process, they remain discriminatory in that not all states' compliance is regularly assessed. ${ }^{80}$ One may also have to accept - hopefully only at an initial stage - some level of opacity towards the public, or even other governmental entities, to ensure that

79 IMO, A.1067/28, Part I, para 7.3.1.

80 The author examined the potential issues related to unilateral trade sanctions by the European Union in a previous publication. See Guggisberg 2017 (supra note 13) pp. ${ }^{160-166 . ~}$ 
states willingly share their issues with auditors. A further sizable incentive can be found in the provision of technical support, which could become linked to a prior identification of weaknesses through an audit procedure. Finally, while having one's performance assessed by external specialists may be uncomfortable at first, it could also decrease the burden that self-reporting obligations under various instruments place on many developing countries.

Another prerequisite to the further development of an audit scheme is the identification of the most adequate institution which could potentially be put in charge of the procedure. The FAO has demonstrated experience in several relevant features of such a scheme. Indeed, to this date, in addition to the many capacity-development projects it supports, the FAO has supervised the drafting of the VGFSP and is to receive the results of states' assessments. It is also overseeing the establishment of a regular questionnaire under the PSMA and is entrusted with quantitatively analysing the responses. It is furthermore a centralized depository of states' laws relevant to fishing activities. The FAO has thus already proven its ability to develop universal criteria to be used as benchmarks, to coordinate a self-assessment form, and to gather information on laws and policies - three elements of the procedure which gradually established itself in shipping. Hence, if given the required mandate and necessary resources, the FAO appears to be in a position of choice to develop and implement an audit mechanism.

\section{Acknowledgements}

The author acknowledges support from the Nippon Foundation Nereus Program, a research collaboration between Utrecht University and 17 partner institutions. 